\title{
Health Promotion Behavior Among Hypertensive and Normotensive Armenian Americans
}

\author{
Zoya Minasyan \\ West Coast University \\ Leslie C. Hussey \\ Walden University \\ Kathleen Brewer \\ Walden University
}

Hypertension presents a significant health risk to both developed and developing countries, affecting approximately 78 million Americans of various ethnic backgrounds. Though a great deal of research about hypertension and minority groups has been published, no studies were located about hypertension in the Armenian American population, despite evidence of health disparities in this population. The purpose of the present study was to examine the differences in health promotion behavior between hypertensive and normotensive Armenian Americans. A quantitative approach was used to examine the relationship between hypertensive status and health promotion behavior. With a sample size of $n=204$, this study found that while there was no significant difference in overall Health Promotion Lifestyle Profile scores, the normotensive group scored higher on physical activity and stress management. These differences remained significant even when controlling for body mass index. Additionally, the study found high smoking rates and elevated body mass index across both samples. These results suggest that interventions that target stress management and physical activity and use the cultural strengths of interpersonal relationships and spiritual growth may be the most effective. This information may be used as a foundation in future interventional studies and may create significant social change by decreasing hypertension among the Armenian American population and increasing awareness of risk factors and prevention.

Keywords: health promotion, hypertension, Armenian American, immigrant population, health promotion model, health promotion behavior

\section{Introduction}

Hypertension, defined by the American Heart Association (AHA) as a persistent blood pressure (BP) reading of 140/90 $\mathrm{mmHg}$ or greater, directly contributes to stroke and cardiovascular disease, one of the leading causes of death in the United States (Pickering et al., 2005; Yoon, Fryar, \& Carroll, 2015). Normotension, by contrast, was defined by the AHA as a persistent BP reading of less than 120/80 mmHg ( (Pickering et al., 2005). The 2015-2016 National Health and Nutrition Examination Survey reflected a national prevalence for hypertension of $29 \%$ that increased with age and varied greatly depending on ethnicity (Fryar, Ostchega, Hales, Zhang, \& Kruszon-Moran, 2017). Hypertension results in an estimated annual cost of $\$ 48.6$ billion, and without any intervention, that number is projected to reach $\$ 274$ billion by 2030 (Mozaffarian et al., 2016). Current research 
suggests that controlling BP results in a significant reduction in morbidity and mortality, which also decreases medical costs (Mozafarian et al., 2016). Additionally, the Joint National Committee on the Prevention, Detection, Evaluation, and Treatment of High Blood Pressure recommends nonpharmacologic lifestyle changes as the primary mechanism for treatment and prevention of hypertension (James et al., 2014).

Minority and immigrant groups have disproportionally high rates of hypertension and often have less access to healthcare services than White, native-born Americans (Lukoschek, 2003; Zallman et al., 2013). The rates of hypertension among ethnic groups are affected by a variety of risk factors, including foreign-born status, language spoken at home, health promotion behavior, education, income, and socioeconomic status (Tailakh et al., 2014; Yi, Elfassy, Gupta, Myers, \& Kerker, 2014). Understanding the health promotion behaviors of hypertensive and normotensive members of various ethnic groups is vital for conducting effective research and creating future interventions to control and prevent hypertension in these communities (Chow et al., 2013). Despite this, no formal research had been conducted that explored the unique attributes of hypertension and health promotion behavior among Armenian Americans, a diasporic community comprised largely of first and second generation immigrants.

Despite the paucity of data, there is some evidence that Armenian Americans have higher risk factors for hypertension than the general population. Los Angeles County Department of Public Health (2015) survey data showed that while the overall county smoking rate was $13.3 \%$, the rate among foreign-born Whites (which would include Armenian immigrants) was $17.7 \%$, while the rate for U.S.-born Whites was $12.2 \%$. In a community sample of Armenian Americans, approximately $35 \%$ of males and $28 \%$ of females had high BP, while $37.7 \%$ of males and $34.57 \%$ of females had prehypertensive BP levels (Naccashian, Hattar-Pollara, Ho, \& Ayvazian, 2018). In that same sample, $82 \%$ of males and $76 \%$ of females had a body mass index (BMI) in the overweight or obese range (Naccashian et al., 2018). Additionally, foreign-born Whites who emigrated from countries with higher rates of hypertension tend to have higher rates of hypertension than native-born Whites and foreign-born Americans from others ethnic groups (Yi et al., 2014). Researchers have shown that hypertension prevalence in Armenia is quite high; one fourth of the population is affected (Tadevosyan, Petrosyan, \& Martirosyan, 2013). Hypertension-related morbidity and mortality rates are on the rise in Armenia (Tadevosyan et al., 2013). This could be partially attributed to Armenian's myriad of risk factors, which include one of the highest rates of smoking prevalence in the world, a diet heavy in sugary jams, salty canned vegetables, and preserved meats and high rates of physical inactivity (Tadevosyan et al., 2013).

Researchers have suggested that health promotion behavior, including diet, physical activity, and strong interpersonal connections can be improved through education (Shafieyan et al., 2015; Tailakh et al., 2014). Pender's health promotion model provides a theoretical framework based on Bandura's social learning theory, which can be used to measure health promotion behavior and craft interventions for decreasing the number of preventable health problems in a given population (Pender, Murdaugh, \& Parsons, 2015). The health promotion model was created and refined for use among vulnerable populations that experience significant health disparities (Pender et al., 2015). Vulnerable populations include those who do not speak English, ethnic minority groups, recent immigrants, and refugees to the United States (Pender et al., 2015). Though not all Armenian Americans are immigrants, refugees, or non-English speakers, they all belong to an ethnic minority and could therefore be subject to health disparities that affect the incidence, prevalence, mortality, and burden of disease among this community (Pender et al., 2015). Evaluation of health promotion behavior is conducted using the Health Promotion Lifestyle Profile (HPLP-II). The test-retest 
reliability of the HPLP-II has shown a score of .89 with a Cronbach's alpha of .94, indicating very high levels of reliability and validity (Walker, Sechrist, \& Pender, 1995).

Socioeconomic barriers have historically created difficulties in research and outreach toward vulnerable populations. To create and foster social change, it is vital to overcome these barriers and bring targeted, culturally specific healthcare to these groups (Pender et al., 2015). The lack of health literacy among vulnerable populations has been associated with worse health status, poorer health knowledge, increased hospitalization, and decreased participation in preventative activities (Pender et al., 2015). Greater health literacy can result in medical and health decisions that create better health outcomes (Pender et al., 2015). The economic burden of health disparities has been estimated at $\$ 1.24$ trillion; if proper health promotion education was provided to these communities along with preventative healthcare, it is likely that this economic burden could be at least partially relieved (Pender et al., 2015). However, more research is needed to fully assess and understand the barriers to and facilitators of health promotion behavior.

\section{Method}

\section{Pilot Study}

At least $49 \%$ of the Armenian American population in Los Angeles, California, is not fluent enough in English to understand the statements and questions on the HPLP-II, the consent document, the demographics, and the medical history (City of Glendale, California, Community Development and Housing Neighborhood Services, 2002). A pilot study was conducted with the purpose of translating these documents into Armenian. The methods for translation were based on those outlined by Sousa and Rojjanasrirat (2011) for the translation and validation of an instrument. First, the instrument was translated by a bilingual professor from a Southern California community college. That translation and the original English version were then sent to a professional translation company. The researcher, a bilingual Armenian American, created an additional initial translation. All three translations were combined into one revision to achieve clarity and accuracy. This version was then submitted to an Armenian editor who ensured content was clear, well structured, and culturally appropriate.

Next, two experts were given the Armenian HPLP-II and were asked to back translate the instrument into English. Both of these experts were native English speakers who learned Armenian as a second language. Neither expert was familiar with the HPLP-II, though one was familiar with healthcare concepts. The other expert was familiar with English colloquialisms and idiomatic English. Once the initial back translation was completed, the researcher met with both experts to work through any items that seemed to lose meaning through translation.

After updating the Armenian translation of the HPLP-II, the two experts, the researcher, and a bilingual healthcare worker met together and went over each question to ensure clarity, consistency, and translation. No item was considered complete until the entire committee had reached consensus on wording and translation. After making edits to wording, the committee reached consensus on all 52 items. The researcher then took the Armenian instrument to five native Armenian speakers and asked them to read through the questions, then repeat back what they perceived the question to be asking. This allowed the researcher to make sure that none of the questions were worded in ways that were unclear or caused cultural misunderstandings. 
Finally, the researcher asked nine bilingual community members to evaluate each question in both Armenian and the original English and then rate them using a Likert scale of 1-4 where $1=$ not equivalent, $2=$ unable to assess equivalence, $3=$ equivalent with minor alterations, and $4=$ very equivalent and succinct. The item content validity index (I-CVI) was assessed by the average score given by all experts, and the average was required to be greater than or equal to .78. The scale content validity index (S-CVI) was assessed by averaging all of the responses, and the average was required to be greater than or equal to .90. Cronbach's alpha was run to test for internal consistency which yielded a score of 0.936 .

The I-CVI was calculated through the averaging method described by Polit and Beck (2008). Briefly, the I-CVI is the number of experts giving an equivalent rating at the item level. Because this scale measures agreement, nine experts were used so that any significant disagreements would trigger a rewording of the question. Each item was scored by the experts on the Likert scale previously described. The S-CVI was calculated as the average of the number of items that the experts agreed upon. The average approach of this calculation was chosen due to the number of experts. Additionally, Polit and Beck (2008) recommended this method for scale-level CVIs.

The I-CVI score was 0.90, which exceeded the required score of 0.78 and reflected a high level of content equivalence. The S-CVI was assessed by averaging all responses to all questions, with a total score of 0.96, which exceeded the required score of 0.90 . This reflected a high level of agreement between experts at the scale level. A test for Cronbach's alpha yielded a score of 0.936, reflecting a high level of internal consistency. With these scores, the translated instrument was ready for research on health promotion in Armenian American populations.

\section{Design}

This study used a cross-sectional, descriptive design. A quantitative approach was used to gather and analyze information regarding lifestyle, behavior, and physiological factors and their relationship to hypertension in this population. The independent variable in this study was hypertensive status and was divided into the categories of hypertensive and normotensive. Because $\mathrm{BP}$ can fluctuate throughout the day due to variables including exercise and caffeine consumption, participants were considered to be hypertensive if they had been previously diagnosed as hypertensive, prescribed BP medication, or prescribed lifestyle changes for high BP. Participants who were not previously diagnosed as hypertensive were considered normotensive for the purposes of this study. Variables included BMI as well as the six subscales of the HPLP-II: Spiritual Growth, Interpersonal Relations, Nutrition, Physical Activity, Health Responsibility, and Stress Management.

\section{Sample and Participants}

This study targeted Armenian Americans in the Los Angeles area over 40 years of age. It was difficult to ascertain the exact size of this population as the census data captured Armenian Americans under the large umbrella category of White; therefore, it was necessary to use other information to estimate this population. According to the U.S. Census' American Community Survey, the approximate population of Armenian Americans in Los Angeles County was 200,000 (U.S. Census Bureau, 2014). No data existed on the age ranges in this group; however, approximately $43 \%$ of the residents of Los Angeles County were 40 years of age or older. The population was therefore estimated at about 85,000 (U.S. Census Bureau, 2014). 
This study used convenience and snowball sampling procedures. These sampling procedures were especially useful for this population, as the inclusion criterion specified both the age and ethnicity of the sample. Inclusion in the study required that participants be (a) 40 years of age or older, (b) selfidentified as Armenian American, and (c) residents of Los Angeles County. Potential participants were disqualified if they were pregnant due to the prevalence of hypertension in pregnancy, or if they were mentally or physically incapable of informed consent (Pickering et al., 2005). Pregnancy was determined through self-reporting. Participants were not required to be fluent in reading or speaking English, as all study materials were available in both Armenian and English. This study was approved by the internal review board, and all participants signed consent forms.

\section{Data Treatment}

Data collected were not attached to names, phone numbers, addresses, or other identifying data. Each participant was assigned a random number that was used to identify their data in lieu of names or other identifiers. Data were collected on paper forms and then entered into a spreadsheet for analysis.

\section{Procedure}

The study population included self-identified Armenian Americans who were over the age of 40 and lived in Los Angeles County. Participants were recruited with flyers that were posted in a local bakery and an adult healthcare center and written in both English and Armenian and via word of mouth. Participants received a $\$ 10.00$ gift card for completing the study. Those who agreed to participate were screened to ensure they could understand the internal review board-approved consent form. All those who were screened were able to understand and agree to provide informed consent. Data collection occurred over the course of 2.5 weeks in early March 2017. Though 206 participants were recruited, one was excluded due to age (38 years old), and the other because the potential participant was a tourist from Armenia. To begin data collection, the participant was asked to sit in a comfortable position in a chair with legs uncrossed where they rested for $5 \mathrm{~min}$. Two separate BP readings were taken at least $1 \mathrm{~min}$ apart and were averaged. If the difference between the two was $>5 \mathrm{mmHg}$, a third measurement was taken (Pickering et al., 2005). The participant's height was measured using the stadiometer and weight was taken using a digital scale.

Each participant then completed a demographic data sheet, medical history, and the HPLP-II. Although the English version of the survey was provided to all participants, most of the participants chose to complete the study in Armenian. Ten participants completed the study in English. If the participants could not read in either English or Armenian, the information was read to them by the researcher, who is fluently bilingual, and their answers were recorded $(n=2)$. The participants were provided with information about their BP and BMI upon completing the study. In the event of any extreme values, the participant was encouraged to see a healthcare provider for further testing.

\section{Measures}

\section{Blood Pressure}

$\mathrm{BP}$ referred to the ratio of systolic to diastolic pressure, where systolic referred to the pressure in the arteries when the heart muscle contracted and diastolic referred to the pressure in the arteries between contractions. BP was measured using an OMRAN HEM-705CP automatic BP monitor (HEM-705CP, Omron Corporation, Tokyo, Japan), which was calibrated and operated according to the standards set forth by the manufacturer (Asmar, Khabouth, Topouchian, El Feghali, \& Mattar, 
2010). BP readings of 140/90 $\mathrm{mmHg}$ and above were considered high, and BP readings below 140/90 mmHg were considered normal.

\section{Hypertension}

Hypertension was defined by the AHA as a persistent BP reading of 140/90 mmHg or greater (Pickering et al., 2005). For the purposes of this study, participants were considered hypertensive if they had been told by a doctor that they were hypertensive or had high BP, and if they had been prescribed medication or lifestyle changes.

\section{Normotension}

Normotension was defined by the AHA as a persistent BP reading of less than $120 / 80 \mathrm{mmHg}$ (Pickering et al., 2005). For the purposes of this study, participants were considered normotensive if they had never been prescribed lifestyle changes or medications to treat hypertension.

\section{BMI}

BMI was measured in kilograms per meters squared. Height was measured with the participant's shoes off using a standing stadiometer, and weight was measured with participant's shoes off using an Omron scale. BMI was considered underweight if it was $<18.5 \mathrm{~kg} / \mathrm{m}^{2}$, healthy weight if it was $18.5-24.9 \mathrm{~kg} / \mathrm{m}^{2}$, overweight if it was $25-29.9 \mathrm{~kg} / \mathrm{m}^{2}$, and obese if it was $\geq 30 \mathrm{~kg} / \mathrm{m} 2$ (World Health Organization, 2017).

\section{Health Promotion}

Health promotion behavior referred to the way an individual actualized well-being, personal fulfillment, and productive living in their own life, while lifestyle referred to discretionary activities that comprised an individual's daily activities and influenced their health (Pender et al., 2015). Overall health promotion behavior was measured using the total score on the HPLP-II, which ranged from 1 to 4, and was calculated by the mean score of the recipient's responses to 52 questions on a 4point Likert scale. Possible answers were 1 (never), 2 (sometimes), 3 (often), or 4 (routinely; Walker et al., 1995). The HPLP-II measured health promotion behaviors using six subscales using the same 4point Likert scale: Health Responsibility, Physical Activity, Nutrition, Interpersonal Relations, Spiritual Growth, and Stress Management (Walker et al., 1995). Participants were evaluated both for their overall HPLP-II score as well as their score on each subscale.

\section{Data Analysis}

SPSS Version 23.0 was used to analyze all data. First, descriptive statistics were generated for the demographics collected. Chi-square and $t$ tests were performed to examine for statistically significance differences across the categorical and continuous variables between the two groups (hypertensive vs normotensive). For all the categories with a cell size of 5 or less, Fisher's exact test was applied.

The BMI values of participants were categorized using the World Health Organization (2017) suggested cutoffs to further investigate the BMI differences between the two groups. After comparing continuous systolic BP readings of participants between different groups using $t$ tests, systolic BP readings were categorized by applying the hypertension classification of the AHA (AHA, 2016). Chi square tests were then used to evaluate any differences in BMI categories and measured $\mathrm{BP}$ categories between the two groups.

Descriptive statistic variables about participant's lifestyles were obtained and summarized in a table. The HPLP-II total mean scores (from all items) and the mean scores for each subscale among 
the two groups were calculated and compared using analysis of variance. The total mean score was calculated by summing responses to all HPLP-II items and dividing them by 52 , the total number of items. Analysis of covariance (ANCOVA) was used to compare the HPLP-II mean scores from all items and the mean scores from each subscale among the two groups with BMI as the covariate. All the assumptions for ANCOVA including assumption of normality, linearity, homogeneity of regression slopes, homogeneity of variances and equality of covariance, and homoscedasticity (equal variance of residuals) were assessed and verified.

The analysis examined the relationship between health promotion behavior as measured by the HPLP-II and hypertension status, while controlling for BMI due to a strong relationship between BMI and hypertension (Go et al., 2014). This analysis also revealed the relationship between various demographic variables and other selected characteristics and hypertension status in the sample. Statistically significant relationships were determined by $p$ values less than .05 on $t$ test, chi-square, analysis of variance, or ANCOVA analysis.

\section{Results}

\section{Descriptive Characteristics}

The total number of participants in the study was $N=204$. The mean age among participants was $68.5(S D=13.0)$ and more than half were female $(59.8 \%)$. All the study participants immigrated to the United States, and on average, they had been living in the United States for 16.65 years ( $S D=$ 9.86). In this sample, $70.6 \%$ were married, and $71.1 \%$ were not employed at the point of data collection. The majority of the study participants were never smokers (68.2\%) and never drinkers $(60.2 \%)$. The average systolic BP measured during the interview was $136.2(S D=18.04)$. Participants had an average weight of $163.3(S D=31.70)$ pounds and an average BMI of $31.5(S D=$ $5.80)$.

Table 1 provides descriptive statistics on sociodemographic and other selected characteristics of the study sample by hypertension status. The gender difference across groups was statistically significant $(p=0.004)$. The frequency of widows in the hypertensive group was almost twice as high as that of the normotensive group ( $27 \%$ vs. $14 \%)$. Hypertensive individuals had lower educational attainment, with more than half of them (55\%) reporting less than a high school education. The difference in education categories between groups was significant $(p=0.001)$. There was no significant difference between the drinking and smoking habits of the hypertensive and normotensive groups. 
Table 1. Sociodemographic and Other Selected Characteristics of Participants by Hypertension Status (Categorical Variables)

\begin{tabular}{|c|c|c|c|c|c|c|}
\hline \multirow[b]{3}{*}{ Characteristics } & \multicolumn{4}{|c|}{ Hypertension Status } & \multirow[b]{3}{*}{$\chi^{2}(d f)$} & \multirow[b]{3}{*}{$p$} \\
\hline & \multicolumn{2}{|c|}{ Hypertensive } & \multicolumn{2}{|c|}{ Normotensive } & & \\
\hline & $N$ & $\%$ & $N$ & $\%$ & & \\
\hline Gender & & & & & $8.9(1)$ & .004 \\
\hline Male & 55 & $49.5 \%$ & 27 & $29.0 \%$ & & \\
\hline Female & 56 & $50.5 \%$ & 66 & $71.0 \%$ & & \\
\hline Marital Status & & & & & $8.9(3)$ & .025 \\
\hline Single & 3 & $2.7 \%$ & 5 & $5.4 \%$ & & \\
\hline Married & 76 & $68.5 \%$ & 68 & $73.1 \%$ & & \\
\hline Divorced & 2 & $1.8 \%$ & 7 & $7.5 \%$ & & \\
\hline Widow & 30 & $27.0 \%$ & 13 & $14.0 \%$ & & \\
\hline Education & & & & & $30.4(4)$ & $<.001$ \\
\hline Less than high school & 62 & $55.9 \%$ & 20 & $21.5 \%$ & & \\
\hline High school & 31 & $27.9 \%$ & 36 & $38.7 \%$ & & \\
\hline Associate degree & 7 & $6.3 \%$ & 19 & $20.4 \%$ & & \\
\hline Bachelor's degree & 11 & $9.9 \%$ & 14 & $15.1 \%$ & & \\
\hline Postgraduate & 0 & $0.0 \%$ & 4 & $4.3 \%$ & & \\
\hline \multicolumn{7}{|l|}{ Employment } \\
\hline Employed full time & 10 & $9.0 \%$ & 35 & $37.6 \%$ & $35.3(3)$ & $<.001$ \\
\hline Employed part time & 3 & $2.7 \%$ & 10 & $10.8 \%$ & & \\
\hline Self-employed & 0 & $.0 \%$ & 1 & $1.1 \%$ & & \\
\hline Not employed & 98 & $88.3 \%$ & 47 & $50.5 \%$ & & \\
\hline Monthly salary/income & & & & & $14.9(5)$ & .004 \\
\hline$<\$ 2,500$ & 84 & $75.7 \%$ & 51 & $54.8 \%$ & & \\
\hline$\$ 2,500-5,000$ & 4 & $3.6 \%$ & 10 & $10.8 \%$ & & \\
\hline$\$ 5,001-7,500$ & 0 & $0.0 \%$ & 4 & $4.3 \%$ & & \\
\hline$\$ 7,501-10,000$ & 2 & $1.8 \%$ & 2 & $2.2 \%$ & & \\
\hline$>\$ 10,000$ & 1 & $.9 \%$ & 0 & $.0 \%$ & & \\
\hline Prefer not to say & 20 & $18.0 \%$ & 26 & $28.0 \%$ & & \\
\hline Health insurance & & & & & $0.38(1)$ & .735, n.s. \\
\hline Yes & 107 & $96.4 \%$ & 88 & $94.6 \%$ & & \\
\hline No & 4 & $3.6 \%$ & 5 & $5.4 \%$ & & \\
\hline Smoking & & & & & $1.88(3)$ & .672, n.s. \\
\hline Current smokera & 25 & $23.1 \%$ & 26 & $28.0 \%$ & & \\
\hline Recent smokerb & 0 & $.0 \%$ & 1 & $1.1 \%$ & & \\
\hline Former smoker ${ }^{c}$ & 7 & $6.5 \%$ & 5 & $5.4 \%$ & & \\
\hline Never smoker & 76 & $70.4 \%$ & 61 & $65.6 \%$ & & \\
\hline Drinking & & & & & $3.12(3)$ & .373, n.s. \\
\hline Never & 67 & $61.5 \%$ & 54 & $58.7 \%$ & & \\
\hline 0-1 drinks per week & 35 & $32.1 \%$ & 35 & $38.0 \%$ & & \\
\hline 2-7 drinks per week & 4 & $3.7 \%$ & 3 & $3.3 \%$ & & \\
\hline$>7$ drinks per week & 3 & $2.8 \%$ & 0 & $0.0 \%$ & & \\
\hline
\end{tabular}

a Someone who smoked within the last month. ${ }^{\mathrm{b}}$ Someone who stopped smoking between 1 month and 1 year ago. ${ }^{c}$ Someone who stopped smoking more than 1 year ago. 


\section{Health Data}

Table 2 shows that the average systolic BP reading among the hypertensive group at the time of data collection $(M=143.3 \mathrm{mmHg}, S D=18.09)$ was statistically different than the average systolic $\mathrm{BP}$ of the normotensive group $(M=127.8 \mathrm{mmHg}, S D=13.99 ; p<.001)$. The average diastolic BP reading among the hypertensive groups at the time of data collection $(M=73.59 \mathrm{mmHg}, S D=11.21)$ was statistically significantly lower than the average diastolic BP reading of the normotensive group (75.22 $\mathrm{mmHg}, S D=8.57)$. While the average body weight did not differ between groups, the hypertensive group had statistically significantly higher average BMI than the normotensive group (32.6 vs. $30.2, p=.003)$.

Table 2. Sociodemographic and Other Selected Characteristics of Participants by Hypertension Status (Continuous Variables)

\begin{tabular}{|c|c|c|c|c|c|c|}
\hline \multirow[b]{3}{*}{ Characteristics } & \multicolumn{4}{|c|}{ Hypertension Status } & \multirow[b]{3}{*}{$t$} & \multirow[b]{3}{*}{$p$} \\
\hline & \multicolumn{2}{|c|}{ Hypertensive } & \multicolumn{2}{|c|}{ Normotensive } & & \\
\hline & $M$ & $S D$ & $M$ & $S D$ & & \\
\hline Systolic blood pre & 143.29 & 18.09 & 127.84 & 13.99 & 6.721 & $<.001$ \\
\hline Diastolic blood pressure & 73.59 & 11.21 & 75.22 & 8.57 & -1.142 & .047 \\
\hline Total household member & 2.46 & 1.28 & 2.90 & 1.11 & -3.248 & $<.001$ \\
\hline Weight in $1 b$ & 164.93 & 29.82 & 161.45 & 33.88 & 0.780 & $.436, n . s$. \\
\hline Body mass index & 32.61 & 6.02 & 30.23 & 5.28 & 2.970 & .003 \\
\hline
\end{tabular}

As seen on Table 3, slightly more than a quarter of individuals (25.8\%) in the normotensive group had a systolic BP reading of less than $120 \mathrm{mmHg}$. Almost a fifth of participants in the hypertensive group (18.9\%) had a systolic BP reading of $160 \mathrm{mmHg}$ or higher, while only $1.1 \%$ of the normotensive group had a BP reading that fell in the Stage 2 hypertension category. A chi-square test revealed a significant difference in systolic BP categories between the hypertensive and normotensive groups $(p$ $<.001)$.

Table 3. Actual Blood Pressure (BP) Reading During Interview by Hypertension Diagnosis Status

\begin{tabular}{lcccc}
\hline \multirow{2}{*}{$\begin{array}{l}\text { Systolic BP Reading } \\
\text { During Interview }\end{array}$} & \multicolumn{4}{c}{ Hypertension Status } \\
\cline { 2 - 5 } (mmH) & \multicolumn{3}{c}{ Hypertensive } & \multicolumn{2}{c}{ Normotensive } \\
\cline { 2 - 5 } & $N$ & $\%$ & $N$ & $\%$ \\
\hline $90-119$ & 8 & $7.2 \%$ & 24 & $25.8 \%$ \\
$120-139$ & 43 & $38.7 \%$ & 49 & $52.7 \%$ \\
$140-159$ & 39 & $35.1 \%$ & 19 & $20.4 \%$ \\
$\geq 160$ & 21 & $18.9 \%$ & 1 & $1.1 \%$ \\
\hline
\end{tabular}

Note. $\chi^{2}(d f)=32.12(3) . p<.001$.

As shown on Table 4, only 5.4\% of those within the hypertensive group had a BMI that fell in the normal weight category. Among normotensive individuals, $11.8 \%$ of participants had a BMI that fell in the normal weight category. Those with hypertension had higher rates of obesity overall, however, there was no statistically significant difference in the distribution of BMI categories between groups $(p=.226)$. 
Table 4. Body Mass Index (BMI) Category Distribution of Participants by Hypertension Diagnosis Status

\begin{tabular}{lcccc}
\hline & \multicolumn{4}{c}{ Hypertension Status } \\
\cline { 2 - 5 } & \multicolumn{3}{c}{ Hypertensive } & \multicolumn{3}{c}{ Normotensive } \\
\cline { 2 - 5 } BMI Category & $N$ & $\%$ & $N$ & $\%$ \\
\hline Underweight $(<18.5)$ & 0 & $0.0 \%$ & 0 & $0.0 \%$ \\
Normal weight (18.5-24.9) & 6 & $5.4 \%$ & 11 & $11.8 \%$ \\
Overweight (25.0-29.9) & 36 & $32.4 \%$ & 35 & $37.6 \%$ \\
Class I obesity (30.0-34.9) & 42 & $37.8 \%$ & 33 & $35.5 \%$ \\
Class II obesity $(35.0-39.9)$ & 14 & $12.6 \%$ & 9 & $9.7 \%$ \\
Class III obesity $(\geq 40)$ & 13 & $11.7 \%$ & 5 & $5.4 \%$ \\
\hline Note.
\end{tabular}

Note. $\chi^{2}(d f)=5.66(4) . p=.226$.

Table 5 shows that rates of diabetes mellitus were statistically significant between groups $(p=.006)$; those with hypertension reported a prevalence of $16.2 \%$, while the normotensive group reported only $4.3 \%$ prevalence.

Table 5. Prevalence of Selected Diseases by Hypertension Status

\begin{tabular}{|c|c|c|c|c|c|c|}
\hline \multirow[b]{3}{*}{ Disease } & \multicolumn{4}{|c|}{ Hypertension Status } & \multirow[b]{3}{*}{$\chi^{2}(d f)$} & \multirow[b]{3}{*}{$p$} \\
\hline & \multicolumn{2}{|c|}{ Hypertensive } & \multicolumn{2}{|c|}{ Normotensive } & & \\
\hline & $N$ & $\%$ & $N$ & $\%$ & & \\
\hline Renal disease & & & & & $1.35(1)$ & .379 \\
\hline Yes & 4 & $3.6 \%$ & 1 & $1.1 \%$ & & \\
\hline No & 107 & $96.4 \%$ & 92 & $98.9 \%$ & & \\
\hline Endocrine disease & & & & & $7.47(1)$ & .006 \\
\hline Yes & 18 & $16.2 \%$ & 4 & $4.3 \%$ & & \\
\hline No & 93 & $83.8 \%$ & 89 & $95.7 \%$ & & \\
\hline Thyroid problems & & & & & $0.38(1)$ & .735 \\
\hline Yes & 4 & $3.6 \%$ & 5 & $5.4 \%$ & & \\
\hline No & 107 & $96.4 \%$ & 88 & $94.6 \%$ & & \\
\hline $\begin{array}{l}\text { Heart failure } \\
\text { congestive heart failure }\end{array}$ & & & & & $2.34(1)$ & .179 \\
\hline Yes & 11 & $9.9 \%$ & 4 & $4.3 \%$ & & \\
\hline No & 100 & $90.1 \%$ & 89 & $95.7 \%$ & & \\
\hline $\begin{array}{l}\text { Poor circulation } \\
\text { in the peripheries }\end{array}$ & & & & & $1.42(1)$ & .295 \\
\hline Yes & 6 & $5.4 \%$ & 2 & $2.2 \%$ & & \\
\hline No & 105 & $94.6 \%$ & 91 & $97.8 \%$ & & \\
\hline
\end{tabular}

\section{Health Promotion Behavior}

The hypertensive group mean score on the health-promoting lifestyle subscale (all items) was 3.21, while the normotensive group mean score was 3.25 . These scores were not statistically significantly different $(p=.49)$. However, both the physical activity $(p=.001)$ and stress management $(p=.004)$ subscales were statistically significant. ANCOVA was applied to examine for possible differences in subscale mean scores by group, while controlling for the potential confounding or mediating effect of BMI. When controlling for BMI, the physical activity scores were significantly different with $p=.007$ 
and an adjusted $R^{2}=0.078$. When controlling for BMI, the stress management scores were significantly different with a $p=.012$ and adjusted $R^{2}=0.040$.

\section{Discussion}

The key findings of this study include both demographic and health promotion behavioral factors. Though the smoking rate for the White population in Los Angeles is around 12\%, the rate of current smokers in this study was more than double (25.4\%). The majority of this sample was insured (95.6\%) and made less than $\$ 2,500$ monthly. The hypertensive group had lived in the United States for an average of 14.65 years, while the normotensive group had lived in the United States for an average of 19.05 years. The average weight between the two groups did not differ significantly, however, the BMI of the hypertensive group (32.61) was statistically significantly higher than the normotensive group (30.23). Though the normotensive group had never been diagnosed with hypertension by definition, when BP readings were taken, $52.7 \%$ were prehypertensive, $20.4 \%$ were at Stage 1 hypertension, and 1.1\% were at Stage 2 hypertension, according to the AHA's (2016) guidelines. Though the purpose of this study was not to diagnose, these findings suggest that participants who thought that they were normotensive may have had undiagnosed hypertension.

There were no statistically significant differences between the two groups overall health promotion behavior scores. However, the lowest HPLP-II subscale scores among the hypertensive sample were physical activity and stress management, each of which were significantly lower than the normotensive groups scores. This was similar to Jadalla, Hattar, and Schubert's (2015) study on Arab Americans, which found HPLP-II scores were lowest in physical activity and highest in spiritual growth. Yi et al. (2014) found that foreign-born Whites who immigrated to the United States had higher levels of hypertension than native-born Whites, especially when there were higher levels of hypertension in their countries of origin. The findings of this study also suggest that those who have spent more time living in the United States have a lower prevalence of hypertension. Tadevosyan et al. (2013) found low levels of both awareness and control of hypertension in Armenians, which was also present in this sample; approximately $73 \%$ of the normotensive sample had BP readings in the prehypertensive and hypertensive ranges, showing a potential lack of awareness of hypertensive status. Approximately $93 \%$ of the hypertensive sample had BP readings at prehypertensive or higher, showing a potential lack of BP control.

The risk factors for hypertension were present in the hypertensive sample. The hypertensive participants were more likely to be widowed than the normotensive group ( $27 \%$ vs. $14 \% ; p=.025)$ and more likely to live on less than $\$ 2,500$ per month $(75.7 \%$ vs. $54.8 \% ; p=.004)$. The hypertensive group also had lower levels of education, with $55.9 \%$ possessing a less than high school education, as opposed to $21.5 \%$ of the normotensive sample $(p<.001)$. On average, hypertensive participants were older $(M=74.8)$ than the normotensive participants $(M=60.96)$ and had significantly higher BMI $(M=32.61)$ than the normotensive participants $(M=30.23)$. Almost the entire sample was insured, in contrast to Zallman et al.'s study (2013), which suggested that the disparity in hypertension status between immigrants and native-born Americans was due to insurance coverage.

\section{Limitations}

The generalizability of this study is limited by the convenience sampling strategy. The data were gathered from recipients at two locations throughout 2.5 weeks in early March 2017. The study included only Armenian American immigrants, so results should not be generalized to other ethnic minority groups. This study did not include any intervention, but rather aimed to create a baseline of 
data for future interventional studies. This study did not provide statistics on the prevalence of hypertension among this community. This study included only those 40 years of age and older who were not pregnant.

\section{Theoretical Findings}

It has been theorized that the detection and treatment of hypertension in ethnic minority communities could be improved through the use of culturally specific interventions (Shafieyan et al., 2015; Tailakh et al., 2014). One way to identify areas of need is to examine the different subscales of the HPLP-II to identify the areas of need for a given community. The scales that showed a significant difference between groups were physical activity and stress management. Further, these were the lowest scoring items for the hypertensive group. As both physical activity and stress management are recommended as lifestyle changes for those diagnosed with hypertension, this finding suggests that a targeted, culturally appropriate intervention may be helpful for this community. Both groups' highest scores were in interpersonal relations and spiritual growth, which reflects the tightly knit community culture of Armenian Americans. This community prioritizes social gatherings in private homes, community centers, and churches, and uses these spaces to facilitate and maintain social connection.

To strengthen the available research regarding this population, it would be advisable to conduct a similar study in Armenia. Because those who had spent less time in the United States typically had higher levels of hypertension, creating a baseline of health promotion data in Armenia could hold interesting implications regarding acculturation for those who emigrate from Armenia to the United States. Because the census does not capture Armenian Americans as a distinct minority group, it would be useful to gather hypertension prevalence information to inform future studies. Though the sample size of this study was chosen through a power analysis with medium power, a follow-up study with a significantly larger sample size could provide more nuance to the findings. It would also be useful to gather more thorough health data.

\section{Conclusions and Implications for Future Research}

Though it has been well established in the literature that hypertension is related to a wide variety of diseases and health complications and that rates of hypertension vary widely among different ethnic groups, there was a paucity of data regarding hypertension in Armenian American communities. The development of hypertension is caused by both modifiable and nonmodifiable risk factors and can be treated through a combination of lifestyle, medication, and health promotion behavior. Future studies should focus on interventions that are sensitive to the cultural factors of Armenian Americans. For example, interventions could focus on increasing physical activity and stress management using the strong interpersonal relationships and spiritual focus of this ethnic minority group. It may be useful to create interventions in both the interpersonal realm (churches and community centers) and the medical realm (doctor's offices and clinics). Because many of those in the normotensive sample had BP readings that were prehypertensive and higher, it would be advisable to conduct a follow-up study that measures awareness and an intervention that increases both awareness and treatment for hypertension. 


\section{References}

American Heart Association [AHA]. (2016). The facts about high blood pressure. Retrieved from http://www.heart.org/HEARTORG/Conditions/HighBloodPressure/GettheFactsAboutHighBlo odPressure/The-Facts-About-High-Blood-Pressure_UCM_002050_Article.jsp\#.WPZ0lojyuUk

Asmar, R., Khabouth, J., Topouchian, J., El Feghali, R., \& Mattar, J. (2010). Validation of three automatic devices for self-measurement of blood pressure according to the International Protocol: The Omron M3 Intellisense (HEM-7051-E), the Omron M2 Compact (HEM 7102-E), and the Omron R3-I Plus (HEM 6022-E). Blood Pressure Monitoring, 15, 49-54. doi:10.1097/mbp.0b013e3283354b11

Chow, C. K., Teo, K. K., Rangarajan, S., Islam, S., Gupta, R., Avezum, A., ... Kazmi, K. (2013). Prevalence, awareness, treatment, and control of hypertension in rural and urban communities in high-, middle-, and low-income countries. Journal of the American Medical Association, 310, 959-968. doi:10.1001/jama.2013.184182

City of Glendale, California, Community Development and Housing Neighborhood Services. (2002) The Glendale quality of life project. Retrieved from http://www.glendaleca.gov/government/departments/community-development/neighborhoodservices/brochures-flyers-and-reports/quality-of-life-report

Fryar, C. D., Ostchega, Y., Hales, C. M., Zhang, G., \& Kruszon-Moran, D. (2017). Hypertension prevalence and control among adults: United States, 2015-2016. NCHS Data Brief, 289, 1-8. Retrieved from https://europepmc.org/abstract/med/29155682

Go, A. S., Mozaffarian, D., Roger, V. L., Benjamin, E. J., Berry, J. D., Blaha, M. J., ... Stroke, S. S. (2014). Heart disease and stroke statistics-2014 update: A report from the American Heart Association. Circulation, 129, e28. doi:10.1080/15398285.2014.902284

Jadalla, A. A., Hattar, M., \& Schubert, C. C. (2015). Acculturation as a predictor of health promoting and lifestyle practices of Arab Americans: A descriptive study. Journal of Cultural Diversity, 22,15 .

James, P. A., Oparil, S., Carter, B. L., Cushman, W. C., Dennison-Himmelfarb, C., Handler, J., ... Smith, S. C. (2014). 2014 evidence-based guideline for the management of high blood pressure in adults: Report from the panel members appointed to the Eighth Joint National Committee (JNC 8). Journal of the American Medical Association, 311, 507-520. doi:10.1001/jama.2013.284427

Los Angeles Department of Public Health. (2015). LA County health survey [Excel spreadsheet]. Retrieved from http://www.publichealth.lacounty.gov/ha/LACHSDataTopics2015.htm

Lukoschek, P. (2003). African Americans' beliefs and attitudes regarding hypertension and its treatment: A qualitative study. Journal of Health Care for the Poor and Underserved, 14, 566-587. doi:10.1353/hpu.2010.0690

Mozaffarian, D., Benjamin, E. J., Go, A. S., Arnett, D. K., Blaha, M. J., Cushman, M., ... Howard, V. J. (2016). Executive summary: Heart disease and stroke statistics-2016 update: A report from the American Heart Association. Circulation, 133, 447. doi:10.1161/CIR.0000000000000366

Naccashian, Z., Hattar-Pollara, M., Ho, C., \& Ayvazian, S. P. (2018). Prevalence and predictors of diabetes mellitus and hypertension in Armenian Americans in Los Angeles. The Diabetes Educator, 44, 130-143. doi:10.1177/0145721718759981 
Pender, N. J., Murdaugh, C. L., \& Parsons, M. A. (2015). Health promotion in nursing practice (7th ed.) Harrisonburg, VA: Pearson.

Pickering, T. G., Hall, J. E., Appel, L. J., Falkner, B. E., Graves, J., Hill, M. N., ... \& Roccella, E. J. (2005). Recommendations for blood pressure measurement in humans and experimental animals, Part 1: Blood pressure measurement in humans: A statement for professionals from the Subcommittee of Professional and Public Education of the American Heart Association Council on High Blood Pressure Research. Hypertension, 45, 142-161. doi:10.1161/01.cir.0000154900.76284.f6

Polit, D. F., \& Beck, C. T. (2008). Nursing research: Generating and assessing evidence for nursing practice. Philadelphia, PA: Wolters Kluwer.

Shafieyan, Z., Qorbani, M., Mehr, B. R., Mahboubi, M., Rezapour, A., Safari, O., ... Mansourian, M. (2015). Association between lifestyle and hypertension in patients referred to health care centers of Ilam City in 2014. Global Journal of Health Science, 8, 161. doi:10.5539/gjhs.v8n6p161

Sousa, V. D., \& Rojjanasrirat, W. (2011). Translation, adaptation and validation of instruments or scales for use in cross-cultural health care research: A clear and user-friendly guideline. Journal of Evaluation in Clinical Practice, 17, 268-274. doi:10.1111/j.13652753.2010.01434.x

Tadevosyan, A., Petrosyan, V., \& Martirosyan, H. (2013). Control of high blood pressure in Gavar region (Master of Public Health integrated experience project). School of Public Health, American University of Armenia, Yerevan, Armenia. Retrieved from http://sph.aua.am/master-projects_2013/

Tailakh, A. K., Evangelista, L. S., Morisky, D. E., Mentes, J. C., Pike, N. A., \& Phillips, L. R. (2014). Acculturation, medication adherence, lifestyle behaviors, and blood pressure control among Arab Americans. Journal of Transcultural Nursing,27, 57-64. doi:10.1177/1043659614526456

U.S. Census Bureau. (2014). People reporting single ancestry 2010-2014 American Community Survey 5-year estimates. Retrieved from http://factfinder.census.gov/faces/tableservices/jsf/pages/productview.xhtml?pid=ACS_14_5Y R_B04004\&prodType=table

Walker, S., Sechrist, K., \& Pender, N. (1995). The health-promoting lifestyle profile II. Nurse Researcher36, 76-81. doi:10.1097/00006199-198703000-00002

World Health Organization. (2017, January 8). BMI classification. Retrieved from http://apps.who.int/bmi/index.jsp?introPage=intro_3.html

Yi, S., Elfassy, T., Gupta, L., Myers, C., \& Kerker, B. (2014). Nativity, language spoken at home, length of time in the United States, and race/ethnicity: Associations with self-reported hypertension. American Journal of Hypertension, 27, 237-244. doi:10.1093/ajh/hpt209

Yoon, S. S., Carroll, M. D., \& Fryar, C. D. (2015). Hypertension prevalence and control among adults: United States, 2011-2014. NCHS Data brief, 220, 1-8.

Zallman, L., Himmelstein, D. H., Woolhandler, S., Bor, D. H., Ayanian, J. Z., Wilper, A. P., \& McCormick, D. (2013). Undiagnosed and uncontrolled hypertension and hyperlipidemia among immigrants in the U.S. Journal of Immigrant and Minority Health, 15, 858-865. doi:10.1007/s10903-012-9695-2 
The Journal of Social, Behavioral, and Health Sciences is an open-access, peer-reviewed, online interdisciplinary journal focusing on research findings that address contemporary national and international issues. Its objectives are to (a) encourage dialogue between scholars and practitioners in the social, behavioral, and health sciences that fosters the integration of research with practice; (b) promote innovative models of interdisciplinary collaboration among the social, behavioral, and health sciences that address complex social problems; and (c) inform the relationship between practice and research in the social, behavioral, and health sciences.

Walden University Publishing: http://www.publishing.waldenu.edu 